Marquette University

e-Publications@Marquette

School of Dentistry Faculty Research and

Publications

Dentistry, School of

8-2019

\title{
Effect of Finish Line Design and Metal Alloy on The Marginal and Internal Gaps of Selective Laser Melting Printed Copings
}

Adel Al Maaz

Marquette University

Geoffrey A. Thompson

Marquette University, geoffrey.thompson@marquette.edu

Carl Drago

Marquette University

Hongseok An

Marquette University

David W. Berzins

Marquette University, King Saud University, david.berzins@marquette.edu

Follow this and additional works at: https://epublications.marquette.edu/dentistry_fac

Part of the Dentistry Commons

\section{Recommended Citation}

Al Maaz, Adel; Thompson, Geoffrey A.; Drago, Carl; An, Hongseok; and Berzins, David W., "Effect of Finish Line Design and Metal Alloy on The Marginal and Internal Gaps of Selective Laser Melting Printed Copings" (2019). School of Dentistry Faculty Research and Publications. 351.

https://epublications.marquette.edu/dentistry_fac/351 
Marquette University

e-Publications@Marquette

\section{Dentistry Faculty Research and Publications/School of Dentistry}

This paper is NOT THE PUBLISHED VERSION; but the author's final, peer-reviewed manuscript. The published version may be accessed by following the link in the citation below.

Journal of Prosthetic Dentistry, Vol. 122, No. 2 (August 2019): 143-151. DOI. This article is (C Elsevier and permission has been granted for this version to appear in e-Publications@Marquette. Elsevier does not grant permission for this article to be further copied/distributed or hosted elsewhere without the express permission from Elsevier.

\section{Effect of Finish Line Design and Metal Alloy on The Marginal and Internal Gaps of Selective Laser Melting Printed Copings}

\section{Adel Al Maaz}

Graduate Prosthodontics, Marquette University School of Dentistry, Milwaukee, WI Geoffrey A. Thompson

Graduate Prosthodontics, Marquette University School of Dentistry, Milwaukee, WI

Carl Drago

Graduate Prosthodontics, Marquette University School of Dentistry, Milwaukee, WI Hongseok An

Department of General Dental Sciences, Marquette University School of Dentistry, Milwaukee, WI David Berzins

Department of General Dental Sciences, Marquette University School of Dentistry, Milwaukee, WI 


\section{Abstract}

\section{Statement of problem}

Selective laser melting (SLM) technology has been introduced for printing metal dental restorations from Co- $\mathrm{Cr}$ base alloys or Au-Pt high noble alloys. However, information regarding the fit of restorations fabricated by using this technique is limited.

\section{Purpose}

The purpose of this in vitro study was to determine the effect of 3 different finish line designs on the marginal and internal gaps of metal copings made from a base ( $\mathrm{Co}-\mathrm{Cr}$ ), high noble ( $\mathrm{Au}-\mathrm{Pd}-\mathrm{Ag}$ ), and noble alloy (Co-Pd) by using the SLM technology.

\section{Material and methods}

Three Ivorine right maxillary central incisors were prepared with a chamfer, deep chamfer, or shoulder finish line. The preparations were scanned by using a TRIOS scanner, and a total of 90 dies were printed using DPR 10 Resin ( $30 \times 3$ finish line designs). Ten SLM copings were fabricated for each margin design and metal alloy combination for a total of 90 copings ( $10 \times 3$ finish line designs $\times 3$ alloys). Copings were cemented onto dies using an autopolymerizing composite-resin luting material. All coping-die assemblies were sectioned buccolingually by using a low-speed diamond saw, and images were obtained by using an inverted bright field metallurgical microscope at $\times 100$ magnification. Marginal and internal gaps were measured at 5 locations: buccal margin, midfacial, incisal, midlingual, and lingual margin. After gap measurements, representative specimens were embedded in autopolymerizing resin and prepared for metallographic examination. A 2-way multivariate analysis of variance (MANOVA) was conducted to determine the overall significance, followed by ANOVA for each dependent variable $(\alpha=.05)$.

\section{Results}

The results indicated that alloy type and finish line had a significant influence on marginal gap of copings $(P<.001)$. Relative to the internal gap, alloy type had a significant effect $(P<.001)$, but the type of finish line had no statistically significant influence $(P=.337)$. No statistically significant interactions occurred. Base alloys were printed with almost no observable porosity, whereas noble and high noble alloys exhibited hot tears and porosity.

\section{Conclusions}

The finish line type did not influence the internal gap between copings and dies, whereas the alloy type influenced the marginal gap between copings and dies. SLM-fabricated Co-Cr copings on teeth prepared with a deep chamfer finish line demonstrated the lowest marginal gap.

Clinical Implications

Selective laser melting-fabricated Co-Cr copings can be recommended for complete-metal single crown restorations.

Many computer-aided design and computer-aided manufacturing (CAD-CAM) workflows are available for the production of dental restorations, ${ }^{1,2,3}$ most based on a subtractive manufacturing or milling process. ${ }^{4}$ Alternatively, the selective laser melting (SLM) technology is an additive process and has been increasingly used for fabrication of printed metal dental restorations. ${ }^{4}$ The principle that SLM systems operate upon is that a standard tessellation language (STL) file is created and subsequently divided into multiple layers using a slicer program. ${ }^{5}$ The slicer program converts the STL file into G-code, which can control automated machines such as an SLM printer. ${ }^{5}$ SLM printers have 3 basic components, a movable build platform, a powerful 
laser, and a powder bed. ${ }^{5}$ The laser forms a part by localized melting of the powder, and as each layer is completed, a piston raises the build platform and a new powder layer is added. ${ }^{5}$ The process is repeated 1 layer at a time until the part is completed. ${ }^{5}$

Properties of metal alloy sintering powders such as composition, melting temperature, particle size distribution, laser beam absorption and reflection coefficients, and thermal conductivity are important considerations for ensuring the desired results. ${ }^{6,7}$ For example, the average powder particle size could affect mechanical properties and sintering kinetics during solidification. ${ }^{6,8,9}$ Printer settings, such as scanning speed, holding time, temperature of the preheated bed, and thickness of each layer, have been reported to affect the strength, density, and quality of the finished parts. ${ }^{2,3,6,10}$ One important goal of all SLM workflows is to minimize thermal distortion, which can be controlled by properly selecting the preheated bed temperature. ${ }^{11}$ In dentistry, SLM has been used to fabricate metal crown copings from Co-Cr or Au-Pt alloys. ${ }^{12,}{ }^{13}$ While early SLM systems deposited layers approximately 30 to $50 \mu \mathrm{m}$ thick per pass, ${ }^{14}$ progressive development of the process has led to better results, and several studies have reported layer thicknesses of approximately $20 \mu \mathrm{m}$ for dental applications. $^{15,16,17,18}$

The gap between a tooth and the restoration has been difficult to describe and measure; furthermore, no standardized tooth replica has been recommended for use in research. ${ }^{19,} 20,21,22,23,24,25,26$ The marginal design, die spacing, and porcelain application may affect the gap $27,28,29,30,31,32,33,34,35$ and confound the assessment of a technique or material. ${ }^{35,}{ }^{36}$ Marginal configuration or integrity is frequently studied with the premise that it may contribute to the development of secondary caries, prosthesis loosening, and eventual clinical failure. ${ }^{37,38,39,40,41,42,43,44,45}$ Marginal fit has been defined as the gap between the prepared tooth and the intaglio surface of the restoration. ${ }^{46}$ It can also be defined as the linear distance between the finish line of the preparation and the margin of the restoration. ${ }^{44}$ Holmes et al ${ }^{47}$ defined the internal gap as a perpendicular measurement from the internal surface of the casting to the axial wall of the preparation. Studies have examined the fit of copings formed by using the SLM technology; however, to the authors' knowledge, no study has used a standardized finish line to assess fit. ${ }^{7,13,48,49,50}$

The purpose of this in vitro study was to determine the effect of 3 different finish line designs on the marginal and internal gaps of metal copings made from high noble, noble, and base alloys by using the SLM technology. Two null hypotheses were considered: finish line designs will have no effect on the marginal accuracy or internal gap of SLM restorations, and the composition of the metal alloy will have no effect on the marginal accuracy or internal gap of SLM restorations.

\section{Material and methods}

Three right maxillary central incisor teeth (Ivorine T1560; Columbia Dentoform Corp) were prepared by the first author using a diamond rotary instrument (Brasseler USA). Each tooth received a different marginal finish line: shoulder margin (S) with a 90-degree axiogingival internal line angle; deep chamfer margin (DC); or chamfer margin (C). Tooth preparations included the following features: $2.0-\mathrm{mm}$ incisal reduction for all 3 groups; 1.5 $\mathrm{mm}$ axial reduction for the $\mathrm{S}$ and $\mathrm{DC}$ groups and $1.0 \mathrm{~mm}$ for the $\mathrm{C}$ group; $1.0-\mathrm{mm}$ marginal width for the $\mathrm{S}$ and DC groups and $0.5 \mathrm{~mm}$ for the $\mathrm{C}$ group; and 12-degree total occlusal convergence for all groups. A laboratory polyvinyl siloxane impression material (Express putty; 3M ESPE) was used to make an index of the unprepared Ivorine teeth (Fig. 1A) and to standardize reduction for each preparation (Fig. 1B). Twelve degrees of total occlusal convergence was rendered by preparing the typodont tooth in a dental surveyor (J.M. Ney Co) (Fig. 2). 

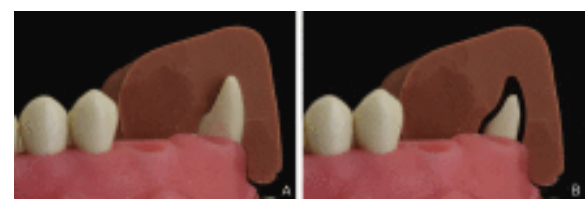

Figure 1 A, Polyvinyl siloxane putty index for preparation of maxillary central incisor. B, Polyvinyl siloxane putty index placed onto prepared right maxillary central incisor.

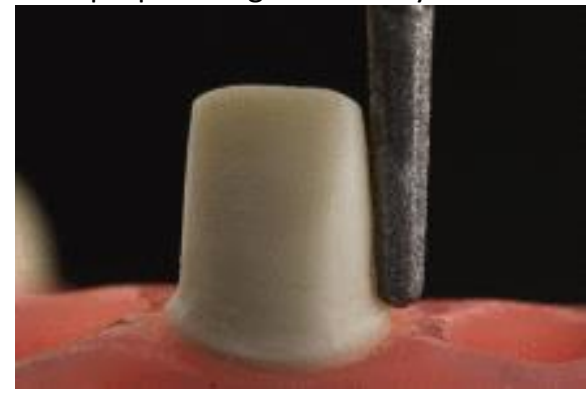

Figure 2 Rotary cutting instrument placed in dental surveyor and held perpendicular to long axis of tooth.

Before scanning the prepared Ivorine teeth, they were attached to an acrylic resin base (GC America). Tooth preparations and their base were scanned by using a chairside scanner (TRIOS; 3Shape), and STL files were used to print 30 identical dies for each finish line (DPR 10 Resin; Carbon3D). The 3Shape CAD design system was used to identify the margin location and to design copings. A uniform die spacer thickness $(25 \mu \mathrm{m})$ was used for each CAD design. SLM copings of approximately $0.3 \mathrm{~mm}$ in thickness were printed (Concept Laser Mlab) from a base alloy (B), a high noble alloy (HN), and a noble alloy (N) (Table 1). Ten specimens per finish line and alloy were produced for a total of 90 specimens ( $10 \times 3$ finish line designs $\times 3$ alloys).

Table 1 Composition of alloys used

\begin{tabular}{|l|l|}
\hline Name of Alloy & Composition, Wt.\% \\
\hline SLM Base $*$ & Co 61, Cr 25, Mo 6, W 5, Si $<1, \mathrm{Fe}<1, \mathrm{Mn}<1$ \\
\hline SLM High Noble (Euro SLM)* & $\mathrm{Au} 40, \mathrm{Pd} 39.9, \mathrm{Ag} 10, \ln 10, \mathrm{Ru}<1$ \\
\hline SLM Noble 25* & $\mathrm{Co} \mathrm{42.75,} \mathrm{Pd} \mathrm{25,} \mathrm{Cr} \mathrm{20,} \mathrm{Mo} \mathrm{12,} \mathrm{B<1}$ \\
\hline
\end{tabular}

SLM, selective laser melting.

*Argen Manufacturing System, Argen Corporation.

After printing, the fit of the copings was visually evaluated by using a light microscope at $\times 12.5$ magnification (Stereo Star Zoom; American Optical). Simulating actual laboratory procedures, internal adjustments were made as necessary to fit the coping on the respective die; adjustments were minimal and infrequent. Copings and dies were assembled using an autopolymerizing composite-resin cement (Panavia 21 EX; Kuraray Noritake Dental Inc) according to the manufacturer's instructions. After cement application, the copings were completely seated on the die. The coping-die assemblies were placed under a 49-N deadweight for 3 minutes. After 3 minutes, the specimens were placed into a $37^{\circ} \mathrm{C}$ incubator (Isotemp Incubator 655D; Fisher Scientific) for an additional 3 minutes. All specimens were stored under ambient conditions until sectioning.

Each specimen was sectioned buccolingually by using a low-speed saw (IsoMet Low Speed Saw; Buehler Ltd) and a $127 \times 0.4-\mathrm{mm}$ diamond wafering blade (Buehler IsoMet; Buehler $\mathrm{Ltd}$ ) with copious water. Two specimens were produced from each coping-die assembly (Fig. 3A). After sectioning, each specimen was notched on the cameo surface by using a round tungsten carbide bur $(0.010 \mathrm{~mm}$; Brasseler USA) to assist with specimen orientation at high magnification (Fig. 3B). Marginal and internal gaps between the coping-die assemblies were measured at 5 locations (Fig. 4) by using an inverted bright field metallurgical microscope at $\times 100$ magnification 
(LECO/Olympus) and a measuring software program (SPOT Software 5.2; SPOT Imaging Solutions). Three measurements were made per location (1-5) and coping-die assembly half, for a total of 30 measurements per coping-die assembly ( 2 coping-die assembly halves $\times 3$ measurements $\times 5$ locations) (Fig. 5 ).

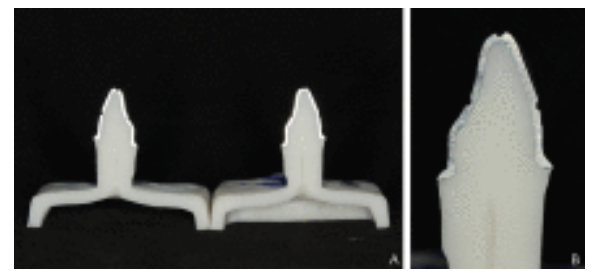

Figure $3 \mathrm{~A}$, Coping-die assembly sectioned in half. B, Sectioned specimen exhibiting notches.

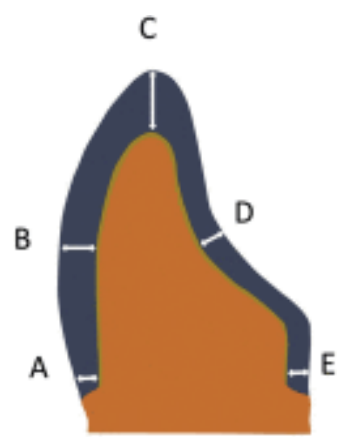

Figure 4 Diagram of measurement locations for margin and internal gaps.

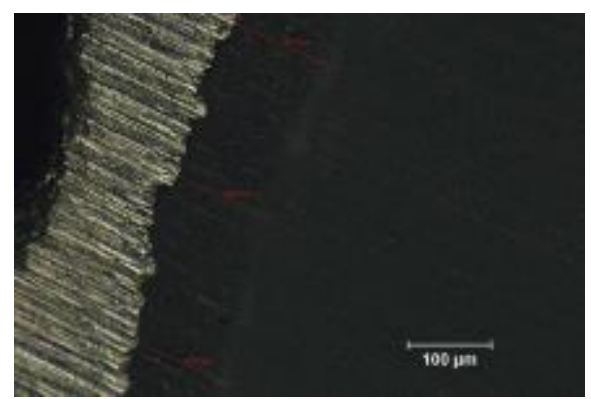

Figure 5 Base alloy; internal gap measurements, midfacial, deep chamfer finish line. Original magnification $\times 15$.

Representative specimens were embedded in autopolymerizing resin (SamplKwick Fast Cure Acrylic Kit; Buehler Ltd). Grinding and polishing were accomplished with a metallographic polisher (Buehler Ltd) and increasingly finer silicon carbide abrasive disks with ample water coolant (180-1000 CarbiMet Abrasive Discs; Buehler Ltd). Final polish was achieved by using a suspension of $1.0-\mu \mathrm{m}$, followed by $0.3-$ and $0.05-\mu \mathrm{m}$, aluminum oxide (Aluminum Oxide Abrasive Powders; Buehler Ltd) and a fine polishing cloth (MicroCloth; Buehler Ltd). After polishing, the specimens were etched with $\mathrm{HCl}(38 \%)$ and $\mathrm{HNO}_{3}(70 \%)$ in a 3:1 ratio, rinsed with water, followed by ethanol, and blow dried. Base and $\mathrm{HN}$ alloy specimens were etched for 1 minute and $\mathrm{N}$ for 40 seconds. The specimens were viewed by using a metallurgical microscope at $\times 5, \times 10$, and $\times 20$ magnifications.

Means and standard deviations under different conditions were compared to test the null hypotheses. The Box test and Levene's test were performed to verify an assumption of equal variances. Material and type of finish line were used as independent variables, and internal and marginal gaps were used as dependent variables. A 2way multivariate analysis of variance (MANOVA) was conducted to determine the overall significance, followed by ANOVA for each dependent variable $(\alpha=.05)$. The Tukey honestly significant difference was used for post hoc comparison $(\alpha=.05)$. All statistical analyses were performed by using a statistical software program (IBM SPSS Statistics, v24; IBM Corp). 


\section{Results}

Of the means of the internal fit of the DC finish line groups, group B showed the greatest internal gap when compared with the other 2 finish line groups $(120 \mu \mathrm{m})$. The $\mathrm{N}$ group with $\mathrm{C}$ finish line had the greatest internal gap $(94 \mu \mathrm{m})$ when compared with the DC or S groups. For the HN group, the internal gap was greatest with the DC finish line $(159 \mu \mathrm{m})$ when compared with $C$ or S. Regarding marginal gap, the mean difference of the $B$ group with $C$ finish line showed the largest gap $(35 \mu \mathrm{m})$ compared with the $D C(20 \mu \mathrm{m})$ or $S$ finish line $(34 \mu \mathrm{m})$ groups. The mean difference of the $N$ group with $C$ finish line showed the largest gap $(59 \mu \mathrm{m})$ compared with DC (35 $\mu \mathrm{m})$ or $\mathrm{S}$ finish line $(44 \mu \mathrm{m})$. In the $\mathrm{HN}$ group, again the $\mathrm{C}$ finish line exhibited the greatest gap $(59 \mu \mathrm{m})$ when compared with the other 2 finish line groups (Table 2 ).

Table 2 Means of internal and marginal gaps $(\mu \mathrm{m})$ of materials with finish lines

\begin{tabular}{|c|c|c|c|c|c|}
\hline Gap & Material & Finish Line & Mean & Standard Deviation & $\mathrm{N}$ \\
\hline \multirow[t]{16}{*}{ Internal gap } & Base alloy & Deep chamfer & 123.3 & 20.5 & 10 \\
\hline & & Chamfer & 122.5 & 9.8 & 10 \\
\hline & & Shoulder & 113.9 & 8.7 & 10 \\
\hline & & Total & 119.9 & 14.2 & 30 \\
\hline & Noble alloy & Deep chamfer & 87.8 & 13.3 & 10 \\
\hline & & Chamfer & 93.5 & 16.2 & 10 \\
\hline & & Shoulder & 87.2 & 13.3 & 10 \\
\hline & & Total & 89.5 & 14.1 & 30 \\
\hline & High noble alloy & Deep chamfer & 158.7 & 19.2 & 10 \\
\hline & & Chamfer & 149.5 & 8.8 & 10 \\
\hline & & Shoulder & 151.3 & 23.6 & 10 \\
\hline & & Total & 153.2 & 18.1 & 30 \\
\hline & Total & Deep chamfer & 123.2 & 34.2 & 30 \\
\hline & & Chamfer & 121.8 & 26.0 & 30 \\
\hline & & Shoulder & 117.5 & 31.1 & 30 \\
\hline & & Total & 120.9 & 30.4 & 90 \\
\hline \multirow[t]{16}{*}{ Marginal gap } & Base alloy & Deep chamfer & 19.8 & 12.1 & 10 \\
\hline & & Chamfer & 34.9 & 10.6 & 10 \\
\hline & & Shoulder & 33.6 & 10.3 & 10 \\
\hline & & Total & 29.4 & 12.7 & 30 \\
\hline & Noble alloy & Deep chamfer & 34.5 & 12.4 & 10 \\
\hline & & Chamfer & 58.5 & 11.0 & 10 \\
\hline & & Shoulder & 43.7 & 11.6 & 10 \\
\hline & & Total & 45.6 & 15.1 & 30 \\
\hline & High noble alloy & Deep chamfer & 32.3 & 12.8 & 10 \\
\hline & & Chamfer & 51.5 & 15.6 & 10 \\
\hline & & Shoulder & 46.1 & 9.3 & 10 \\
\hline & & Total & 43.3 & 14.9 & 30 \\
\hline & Total & Deep chamfer & 28.9 & 13.7 & 30 \\
\hline & & Chamfer & 48.3 & 15.8 & 30 \\
\hline & & Shoulder & 41.1 & 11.5 & 30 \\
\hline & & Total & 39.4 & 15.8 & 90 \\
\hline
\end{tabular}

Multiple comparisons between materials using the Tukey test revealed significant differences among the 3 metal alloys (Table 2) $(P<.001)$. Regarding internal gap, the highest mean difference was found in the HN group 
$(153 \mu \mathrm{m})$, followed by the B group $(120 \mu \mathrm{m})$. The least mean difference was noted in the $\mathrm{N}$ group $(89 \mu \mathrm{m})$. All groups demonstrated significant differences $(P<.001)$ (Table 3$)$. Considering marginal gap, significant differences were found between the $\mathrm{B}$ and $\mathrm{N}$ groups $(P<.001)$ and between the $\mathrm{B}$ and $\mathrm{HN}$ groups $(P<.001)$, but not between $\mathrm{N}$ and $\mathrm{HN}$ groups $(P=.737)$ (Table 3$)$. For internal fit and finish line, no significant differences were found between the $\mathrm{DC}$ and $\mathrm{C}$ groups $(P=.936)$, between the $\mathrm{DC}$ and $\mathrm{S}$ groups $(P=.333)$, or between the $\mathrm{S}$ and $\mathrm{C}$ groups $(P=.531)$. The results showed a significant difference between the $D C$ finish line group and the $C$ and $S$ finish line groups $(P<.001)$. No significant difference was found between the $C$ and $S$ finish line groups $(P=.056)$.

Table 3 Multiple comparisons between materials by post hoc tests

\begin{tabular}{|l|l|l|l|l|l|}
\hline Internal gap & Base alloy & Noble alloy & $30.4 *$ & 4.0 & $<.001$ \\
\hline & & High noble alloy & -33.3 & 4.0 & $<.001$ \\
\hline & Noble alloy & Base alloy & -30.4 & 4.0 & $<.001$ \\
\hline & & High noble alloy & -63.7 & 4.0 & $<.001$ \\
\hline & High noble alloy & Base alloy & $33.3 *$ & 4.0 & $<.001$ \\
\hline & & Noble alloy & $63.7 *$ & 4.0 & $<.001$ \\
\hline Marginal gap & Base alloy & Noble alloy & -16.1 & 3.1 & $<.001$ \\
\hline & & High noble alloy & -13.9 & 3.1 & $<.001$ \\
\hline & Noble alloy & Base alloy & $16.1 *$ & 3.1 & $<.001$ \\
\hline & & High noble alloy & 2.3 & 3.1 & .737 \\
\hline & High noble alloy & Base alloy & $13.9 *$ & 3.1 & $<.001$ \\
\hline & & Noble alloy & -2.3 & 3.1 & .737 \\
\hline
\end{tabular}

$* P$ value $\leq .05$.

As shown in Figure 6A, internal fit exhibited the greatest gap in the DC finish line within the HN alloy group. The smallest gaps were noted in the $\mathrm{S}$ finish line with the $\mathrm{N}$ alloy group. As shown in Figure 6B, marginal fit showed the highest gap between the $\mathrm{C}$ finish line with the $\mathrm{N}$ alloy group. The smallest gaps were observed between the DC finish line in the B alloy group.

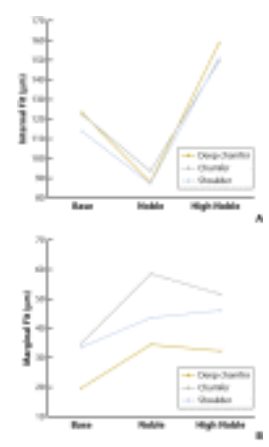

Figure 6 A, Estimated marginal means of internal gap. B, Estimated marginal means of marginal gap.

Figure 7, Figure 8, Figure 9 reveal the microstructure of SLM metal alloys after grinding, polishing, and acid etching. All 3 alloys exhibited a markedly different appearance. The B alloy appeared dense (Fig. 7A) and possessed clearly visible melt pools (Fig. 7B). Noble alloys also displayed melt pools but more porosity and hot tears than either the B or HN alloy (Fig. 8). High noble alloys had fewer distinct melt pools and low porosity but exhibited some hot tears in the copings (Fig. 9).

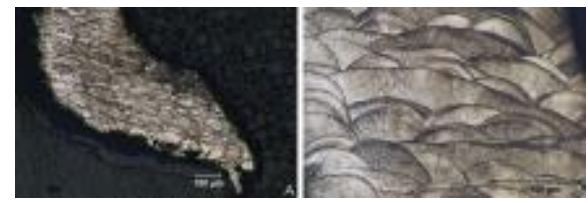


Figure 7 A, Base alloy margin, original magnification $\times 5$. B, Base alloy axial wall, original magnification $\times 20$.
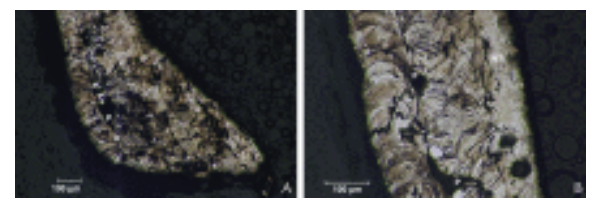

Figure 8 A, Noble metal alloy margin, original magnification $\times 5$. B, Noble metal alloy axial wall, original magnification $\times 10$. $\mathrm{HT}$, hot tear; $\mathrm{P}$, pore.

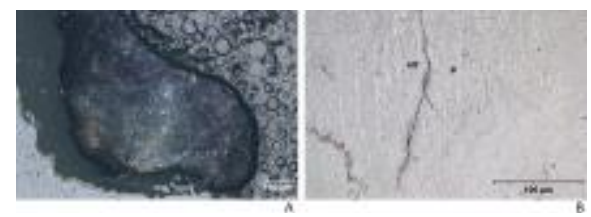

Figure 9 A, High noble alloy metal margin, original magnification $\times 5$. B, High noble metal alloy apex of crown, original magnification $\times 20$. $\mathrm{HT}$, hot tear.

\section{Discussion}

The purpose of this in vitro study was to evaluate the effect of 3 different finish line designs and 3 different alloys on the marginal and internal gaps of SLM-printed copings. The first null hypothesis was rejected as statistically significant results were found among the 3 finish line groups. Therefore, the type of finish line design had a direct effect on observed marginal gaps between the coping-die assemblies. However, no statistical difference was found for internal gap relative to the different finish lines used $(P>05)$. The second null hypothesis was also rejected as statistical differences were found between the type of alloy and the marginal and internal gaps of the SLM-fabricated copings ( $P>.05)$.

Terminology varies when defining the word "fit" as it applies to recording the gap measurements of dental restorations. Holmes et al ${ }^{47}$ took a critical approach to this problem and proposed multiple gap definitions according to differences in contour between the crown and tooth margin. In addition, multiple techniques have been suggested for measuring the marginal and internal gaps of restorations: direct viewing, cross-sectional, impression technique, dental explorer tip, and visual examination. ${ }^{21}$ However, in clinical practice, it has been difficult to describe a gap using a definition. ${ }^{19}$ These are some of the reasons why outcomes differ between investigators when they measure gaps associated with crown and tooth margins. Similar to previous work, this study used the cross-sectional method, which permitted a precise evaluation of fit and a comparison of different margin designs. ${ }^{21,} 45$

Previous investigations used metal, acrylic resin, or natural teeth as dies to measure the marginal gaps between crowns and preparations ${ }^{22,23,24,25,26}$; however, in this study, the dies were printed from DPR 10 Resin (Carbon3D). Some advantages of printed dies are that they may be standardized and can be printed as many times as necessary from a single STL file.

Die spacing methods and seating pressure can influence the fit of restorations. ${ }^{27,}{ }^{28}$ Therefore, die spacer was not manually applied onto the surface of the Ivorine tooth preparations before scanning, rather it was specified during the design process by using a CAD software program. The advantage of software was that it eliminated any differences that may have resulted from applying die spacer by hand.

Well-fitted metal copings may not accurately fit a die after porcelain application. ${ }^{29}$ Anusavice and Carrol $^{30}$ reported that most dimensional changes occurred during the oxidation cycle. Results showed that porcelain firing cycles had a small effect, but grinding and airborne-particle abrasion were primarily responsible for observed changes. In their respective studies, Campbell et $\mathrm{al}^{34}$ and Gemalmaz and Alkumru ${ }^{35}$ reported that 
marginal gaps increased significantly after ceramic application. However, several studies reported no significant differences in marginal gaps after ceramic application. ${ }^{21,31,32}$ Similar to the study by Sulaiman et al ${ }^{36}$ and Beschnidt and Strub, ${ }^{37}$ to maintain focus on the marginal and internal fit of SLM-fabricated copings with their die, the present study measured coping-die assemblies without porcelain veneering.

In a clinical study by McLean and von Fraunhofer, ${ }^{46} 1000$ restorations were followed over a 5-year period, and it was concluded that a marginal gap less than $120 \mu \mathrm{m}$ was clinically acceptable. Although statistically significant differences in marginal fit occurred between different types of finish lines and alloys used in the present study (from $20 \mu \mathrm{m}$ to $59 \mu \mathrm{m}$ ), all results were found to be clinically acceptable.

Quante et $\mathrm{al}^{12}$ investigated the marginal and internal fit of noble and base alloys fabricated by using laser melting technology and found no significant differences in the marginal and internal gaps of the 2 types of alloys studied. The results of the study by Quante et $\mathrm{al}^{12}$ are in contrast with those of the present study, where it was found that alloy type did have a significant effect on the marginal and internal gaps of the SLM-printed copings. There are several reasons why reported outcomes may differ. First, metal powders with dissimilar compositions or particle size distributions affect powder flowability in an SLM process and may affect the density or quality of the part. ${ }^{6}$ Second, variations in laser energy or diameter, layer thickness, and scanning rate can also affect part density and quality. ${ }^{6}$ In both the Quante el al ${ }^{12}$ study and the present work, details of the SLM manufacturing process are unknown; therefore, a comparison of methods is impossible. Finally, the present study used a different procedure for determining gaps compared with Quante et $\mathrm{al}^{12}{ }^{12}$ which may result in differences that are inherent to the method.

During manufacture, the laser must ensure each new layer of powder is melted sufficiently to wet and join with the previous layer. That is one reason for the appearance of melt pools in the metallographic images. Although each metal alloy generally displayed melt pools, they were easiest to observe in the B alloy. Moreover, the B alloy displayed almost no porosity, either between layers or within the powder beads used to form the coping (Fig. 7). However, the $\mathrm{N}$ alloy exhibited numerous large pores and hot tears that, in some instances, appeared to extend through the cross section of the coping (Fig. 8). While the HN alloy generally exhibited smaller and fewer pores than the $\mathrm{N}$ alloy, several hot tears were observed (Fig. 9A). In addition, melt pools in the HN alloy appeared nonexistent in some locations (Fig. 9B).

In this study, SLM technology was less able to reproduce chamfer finish line preparations than heavy chamfer or shoulder finish line preparations with the alloys used. The marginal fit of the B copings with a deep chamfer finish line had the best marginal fit $(8 \mu \mathrm{m}$ to $32 \mu \mathrm{m}$ ). This outcome leads the investigators to propose that Co- $\mathrm{Cr}$ alloy crowns made by using the SLM technology could be an inexpensive alternative to noble alloy SLM restorations. The surface roughness of SLM-fabricated devices can be affected by the laser energy or scanning rate used during manufacture. ${ }^{6}$ A roughened surface may be advantageous compared with conventional castings because it could improve the mechanical bond between the metal and ceramic on the cameo surface or to the luting material on the intaglio surface. However, surface roughness that is too great can trap air or debris, which manifests as porosity in the fired metal-ceramic restoration.

Limitations of this in vitro study include that gaps were not assessed intraorally and that errors in the fabrication and handling of dies were presumed to be negligible. Another limitation of the study was that copings were fabricated by using SLM only; therefore, the influence of porcelain firing on the marginal and internal fit of the crowns was not evaluated. The copings fabricated in this study were not subjected to mechanical cycling or thermocycling. In clinical situations, thermocycling or mechanical cycling may be important factors that affect the long-term success of restorations. Future research directions with SLM-printed metal copings could include flexural strength analysis, corrosion behavior, or porcelain-metal bond strength. 


\section{Conclusions}

Within the limitations of this in vitro study, the following conclusions were drawn:

1. A CAD-CAM fabrication process resulted in the fit of SLM-fabricated metal copings within preestablished, clinically acceptable ranges.

2. Alloys used in this study influenced the marginal gap of SLM-fabricated metal copings.

3. Finish line designs did not significantly influence the internal gap between coping and dies, whereas the alloy type did.

4. SLM-fabricated copings made with a base alloy ( $\mathrm{Co}-\mathrm{Cr}$ ) and a deep chamfer finish line demonstrated the lowest marginal gap when compared with the other groups.

5. Marginal gap was influenced by the type of finish line; deep chamfer finish lines were more accurate than the marginal gaps associated with a chamfer or shoulder finish line.

\section{References}

1. Bindl, A. and Mörmann, W.H. Marginal and internal fit of all-ceramic CAD/CAM crown-copings on chamfer preparations. J Oral Rehabil. 2005; 32: 441-447

2. Miyazaki, T., Hotta, Y., Kunii, J., Kuriyama, S., and Tamaki, Y. A review of dental CAD/CAM: Current status and future perspectives from 20 years of experience. Dent Mater J. 2009; 28: 44-56

3. Fasbinder, D.J. Clinical performance of chairside CAD/CAM restorations. J Am Dent Assoc. 2006; 137 Suppl: 22S-31S

4. van Noort, R. The future of dental devices is digital. Dent Mater. 2012; 28: 3-12

5. Koutsoukis, T., Zinelis, S., Eliades, G., Al-Wazzan, K., Rifaiy, M.A., and Al Jabbari, Y.S. Selective laser melting technique of $\mathrm{Co}-\mathrm{Cr}$ dental alloys: A review of structure and properties and comparative analysis with other available techniques. J Prosthodont. 2015; 24: 303-312

6. in: D. Bourell (Ed.) International solid freeform fabrication symposium: an additive manufacturing conference. University of Texas at Austin, Austin, TX; 2011: 227-238

7. Ucar, Y., Akova, T., Akyil, M.S., and Brantley, W.A. Internal fit evaluation of crowns prepared using a new dental crown fabrication technique: Laser-sintered Co-Cr crowns. J Prosthet Dent. 2009; 102: 253259

8. Kruth, J., Mercelis, P., Van Vaerenbergh, J., Froyen, L., and Rombouts, M. Binding mechanisms in selective laser sintering and selective laser melting. Rapid Prototyp J. 2005; 11: 26-36

9. Takaichi, A., Suyalatu, S., Nakamoto, T., Joko, N., Nomura, N., Tsutsumi, Y. et al. Microstructures and mechanical properties of Co-29Cr-6Mo alloy fabricated by selective laser melting process for dental applications. J Mech Behav Biomed Mater. 2013; 21: 67-76

10. Duret, F. and Preston, J.D. CAD/CAM imaging in dentistry. Curr Opin Dent. 1991; 1: 150-154

11. Agarwala, M., Bourell, D., Beaman, J., Marcus, H., and Barlow, J. Direct selective laser sintering of metals. Rapid Prototyp J. 1995; 1: 26-36

12. Quante, K., Ludwig, K., and Kern, M. Marginal and internal fit of metal-ceramic crowns fabricated with a new laser melting technology. Dent Mater. 2008; 24: 1311-1315

13. Xu, D., Xiang, N., and Wei, B. The marginal fit of selective laser melting-fabricated metal crowns: an in vitro study. J Prosthet Dent. 2014; 112: 1437-1440

14. Vandenbroucke, B. and Kruth, J.-P. Selective laser melting of biocompatible metals for rapid manufacturing of medical parts. Rapid Prototyp J. 2007; 13: 196-203

15. Logozzo, S., Granceschini, G., Kilpela, A., and Blois, L. A comparative analysis of intraoral 3d digital scanners for restorative dentistry. Internet J Med Technol [Internet]. 2011; 5: 1-18 
16. Mangano, F., Gandolfi, A., Luongo, G., and Logozzo, S. Intraoral scanners in dentistry: a review of the current literature. BMC Oral Health. 2017; 17: 149

17. Tamim, H., Skjerven, H., Ekfeldt, A., and Rønold, H.J. Clinical evaluation of CAD/CAM metal-ceramic posterior crowns fabricated from intraoral digital impressions. Int J Prosthodont. 2014; 27: 331-337

18. Kapos, T. and Evans, C. CAD/CAM technology for implant abutments, crowns, and superstructures. Int J Oral Maxillofac Implants. 2014; 29 Suppl: 117-136

19. Groten, M., Girthofer, S., and Pröbster, L. Marginal fit consistency of copy-milled all-ceramic crowns during fabrication by light and scanning electron microscopic analysis in vitro. J Oral Rehabil. 1997; 24: 871-881

20. Kim, M.-J., Choi, Y.-J., Kim, S.-K., Heo, S.-J., and Koak, J.-Y. Marginal accuracy and internal fit of 3-D printing laser-sintered Co-Cr alloy copings. Materials. 2017; 10: 1-13

21. Castellani, D., Baccetti, T., Clauser, C., and Bernardini, U.D. Thermal distortion of different materials in crown construction. J Prosthet Dent. 1994; 72: 360-366

22. Kohorst, P., Brinkmann, H., Dittmer, M.P., Borchers, L., and Stiesch, M. Influence of the veneering process on the marginal fit of zirconia fixed dental prostheses. J Oral Rehabil. 2010; 37: 283-291

23. Kohorst, P., Junghanns, J., Dittmer, M.P., Borchers, L., and Stiesch, M. Different CAD/CAM-processing routes for zirconia restorations: influence on fitting accuracy. Clin Oral Investig. 2011; 15: 527-536

24. Att, W., Komine, F., Gerds, T., and Strub, J.R. Marginal adaptation of three different zirconium dioxide three-unit fixed dental prostheses. J Prosthet Dent. 2009; 101: 239-247

25. Vigolo, P. and Fonzi, F. An in vitro evaluation of fit of zirconium-oxide-based ceramic four-unit fixed partial dentures, generated with three different CAD/CAM systems, before and after porcelain firing cycles and after glaze cycles. J Prosthodont. 2008; 17: 621-626

26. Euán, R., Figueras-Álvarez, O., Cabratosa-Termes, J., Brufau-de Barberà, M., and Gomes-Azevedo, S. Comparison of the marginal adaptation of zirconium dioxide crowns in preparations with two different finish lines. J Prosthodont. 2012; 21: 291-295

27. Ates, S.M. and Yesil Duymus, Z. Influence of tooth preparation design on fitting accuracy of CAD-CAM based restorations. J Esthet Restor Dent. 2016; 28: 238-246

28. Weaver, J.D., Johnson, G.H., and Bales, D.J. Marginal adaptation of castable ceramic crowns. J Prosthet Dent. 1991; 66: 747-753

29. Shillingburg, H.T., Hobo, S., and Fisher, D.W. Preparation design and margin distortion in porcelainfused-to-metal restorations. J Prosthet Dent. 1973; 29: 276-284

30. Anusavice, K.J. and Carroll, J.E. Effect of incompatibility stress on the fit of metal-ceramic crowns. J Dent Res. 1987; 66: 1341-1345

31. Leong, D., Chai, J., Lautenschlager, E., and Gilbert, J. Marginal fit of machine-milled titanium and cast titanium single crowns. Int J Prosthodont. 1994; 7: 440-447

32. Buso, L., Hilgert, E., Neisser, M.P., and Bottino, M.A. Marginal fit of electroformed copings before and after the coction of the porcelain. Braz J Oral Sci. 2004; 3: 409-413

33. Syu, J.Z., Byrne, G., Laub, L.W., and Land, M.F. Influence of finish-line geometry on the fit of crowns. Int J Prosthodont. 1993; 6: 25-30

34. Campbell, S.D., Sirakian, A., Pelletier, L.B., and Giordano, R.A. Effects of firing cycle and surface finishing on distortion of metal ceramic castings. J Prosthet Dent. 1995; 74: 476-481

35. Gemalmaz, D. and Alkumru, H.N. Marginal fit changes during porcelain firing cycles. J Prosthet Dent. 1995; 73: 49-54

36. Sulaiman, F., Chai, J., Jameson, L.M., and Wozniak, W.T. A comparison of the marginal fit of In-Ceram, IPS Empress, and Procera crowns. Int J Prosthodont. 1997; 10: 478-484

37. Beschnidt, S.M. and Strub, J.R. Evaluation of the marginal accuracy of different all-ceramic crown systems after simulation in the artificial mouth. J Oral Rehabil. 1999; 26: 582-593 
38. Sailer, I., Fehér, A., Filser, F., Gauckler, L.J., Lüthy, H., and Hämmerle, C.H.F. Five-year clinical results of zirconia frameworks for posterior fixed partial dentures. Int J Prosthodont. 2007; 20: 383-388

39. Pjetursson, B.E., Tan, K., Lang, N.P., Brägger, U., Egger, M., and Zwahlen, M. A systematic review of the survival and complication rates of fixed partial dentures (FPDs) after an observation period of at least 5 years. Clin Oral Implants Res. 2004; 15: 667-676

40. Jacobs, M.S. and Windeler, A.S. An investigation of dental luting cement solubility as a function of the marginal gap. J Prosthet Dent. 1991; 65: 436-442

41. Della Bona, A. and Kelly, J.R. The clinical success of all-ceramic restorations. J Am Dent Assoc. 2008; 139 Suppl: 8S-13S

42. Knoernschild, K.L. and Campbell, S.D. Periodontal tissue responses after insertion of artificial crowns and fixed partial dentures. J Prosthet Dent. 2000; 84: 492-498

43. Felton, D.A., Kanoy, B.E., Bayne, S.C., and Wirthman, G.P. Effect of in vivo crown margin discrepancies on periodontal health. J Prosthet Dent. 1991; 65: 357-364

44. Balkaya, M.C., Cinar, A., and Pamuk, S. Influence of firing cycles on the margin distortion of 3 allceramic crown systems. J Prosthet Dent. 2005; 93: 346-355

45. Beuera, F., Aggstaller, H., Edelhoff, D., Gernet, W., and Sorensen, J. Marginal and internal fits of fixed dental prostheses zirconia retainers. Dent Mater. 2009; 25: 94-102

46. McLean, J.W. and von Fraunhofer, J.A. The estimation of cement film thickness by an in vivo technique. Br Dent J. 1971; 131: 107-111

47. Holmes, J.R., Sulik, W.D., Holland, G.A., and Bayne, S.C. Marginal fit of castable ceramic crowns. J Prosthet Dent. 1992; 67: 594-599

48. Holmes, J.R., Bayne, S.C., Holland, G.A., and Sulik, W.D. Considerations in measurement of marginal fit. J Prosthet Dent. 1989; 62: 405-408

49. Huang, Z., Zhang, L., Zhu, J., Zhao, Y., and Zhang, X. Clinical marginal and internal fit of crowns fabricated using different CAD/CAM technologies. J Prosthodont. 2015; 24: 291-295

50. Re, D., Cerutti, F., Augusti, G., Cerutti, A., and Augusti, D. Comparison of marginal fit of Lava CAD/CAM crown-copings with two finish lines. Int J Esthet Dent. 2014; 9: 426-435 